\title{
Sensitizing a Gifted Child with Autism Spectrum Disorder towards Social Cognition: From Assessment to Treatment
}

\author{
Sergio Melogno ${ }^{*}$, Barbara Trimarco${ }^{1}$, Maria Antonietta Pinto², Gabriel Levi1 \\ ${ }^{1}$ Department of Paediatrics, Child Neurology and Psychiatry, "Sapienza" University of Rome, Roma, Italy \\ ${ }^{2}$ Department of Social and Developmental Psychology, "Sapienza" University of Rome, Roma, Italy \\ Email: "sergio.melogno@uniroma1.it, barbara.trimarco@uniroma1.it, mariantonietta.pinto@uniroma1.it, \\ gabriel.levi@uniroma1.it
}

Received 21 April 2016; accepted 24 May 2016; published 27 May 2016

Copyright (C) 2016 by authors and Scientific Research Publishing Inc.

This work is licensed under the Creative Commons Attribution International License (CC BY). http://creativecommons.org/licenses/by/4.0/

(c) (i) Open Access

\section{Abstract}

Social cognition difficulties are well documented in children with Autism Spectrum Disorder (ASD). This clinical case study reports on social cognition assessment and treatment of a gifted child, SC (9 years), with ASD and an extraordinarily high verbal IQ (146). The assessment of theory of mind, emotion recognition and pragmatic abilities showed some weaknesses in these areas. The 4month treatment was divided into 14 sessions and was aimed at helping SC to improve his abilities to recognize emotions and comprehend mental states. The main technique used in the intervention was "social reading" with video clips. The initial assessment was repeated after the treatment and in a follow up session. The results of this case study suggest that "social reading" can be considered as a beneficial technique for children with high-functioning ASD, and especially in giftedness conditions.

Keywords

Autism Spectrum Disorder, Gifted Child, Social Cognition, Treatment, Assessment

\section{Introduction}

Autism Spectrum Disorder (ASD) is a complex neurodevelopmental condition characterized by social deficits,

"Corresponding author.

How to cite this paper: Melogno, S., Trimarco, B., Pinto, M.A. and Levi, G. (2016) Sensitizing a Gifted Child with Autism Spectrum Disorder towards Social Cognition: From Assessment to Treatment. World Journal of Neuroscience, 6, 171-180. http://dx.doi.org/10.4236/wjns.2016.62021 
communication difficulties, stereotyped or repetitive behaviors and interests, and sensory issues [1]. ASD and intellectual abilities in the giftedness range represent a particular case of dual exceptionality with several specific implications from a diagnostic and psycho-educational point of view. In this condition, it is necessary, on the one hand, to avoid the risk that excellent performances in some areas of cognitive development conceal issues related to autism, and, on the other hand, to understand how to use the patient's high intellectual potential as a support for the intervention on the weak areas and how to promote it.

To this end, it is necessary to know what are the distinctive features between gifted children with and without ASD [1]. According to Lovecky [2], both groups are characterized by hyper-focus on some cognitive domains and by a strong desire to learn. The issue of the distinctive features between gifted with and without ASD was addressed by various authors as long as the distinction between autism, on the one hand, and Asperger syndrome, on the other [3], was still acknowledged. Children with ASD, especially those with Asperger syndrome, are less able to integrate their special interests, and their abstraction levels are more dependent on the specific contents of cognitive areas. Their intellectual profile shows inconsistencies between verbal and performance IQ, with scores which may be below average in some subtests and in the performance scale of WISC-III [4]. In spite of their high IQs, these children show some difficulties in understanding pragmatic language usages. There are also other differences within the autistic spectrum. Foley-Nicpon, Assouline and Stinson [5] explored cognitive and school profiles and found that gifted children with Autistic Disorder [3] have a lower Verbal Comprehension index in the WISC-IV [6] than those with Asperger syndrome, who generally obtain low scores in math and written expression tests.

Beyond the characteristics of their cognitive profile, social characteristics seem really distinctive between gifted children with and without ASD, and appear in specific difficulties in interaction [7]. Depending on the severity of the social impairment, three patterns can be identified: A) absent; B) moderate; C) severe [7]. Some children belonging to category $\mathrm{C}$ ) show social difficulties which may indicate the presence of an ASD condition. Assouline, Foley Nicpon and Doobay [8] compared the cognitive and neuropsychological profiles of two gifted girls with and without ASD, Carrie and Hannah. Carrie met the criteria for category C and Hannah those for category B. Even though some cognitive patterns were very similar (e.g. language level and narrative skills were very high in both) the girls differed considerably in social skills and executive functioning, which were problematic areas for Carrie, but not for Hannah. Additionally, Carrie had low scores in the affect recognition subtest of NEPSY II [9], which evaluates the ability to recognize emotions from pictures of children's faces, and this suggests another discriminative criterion between the two profiles, namely, difficulties in social cognition.

Social cognition includes the social information processing underlying the individual's social and emotional behavior. More recently, this construct has included various explicit and implicit components, i.e., on the one hand, processing under voluntary control, such as sophisticated inferential reasoning [10] [11], and, on the other, automatic processing, allowing an immediate and unaware tuning with other people. A primary role is played by theory of mind, a theoretical construct later incorporated into the more comprehensive construct of empathy. According to Baron-Cohen [12], empathy includes two components: a cognitive component, that matches the original concept of theory of mind [13], namely the ability of the individual to attribute mental states to others in order to predict and explain their behavior, and an affective component, consisting in the ability to react spontaneously and appropriately to other people's emotional states. Both components contribute to the individual's social adjustment and usually show delays and/or deficits in children with ASD.

Impairments in social cognition are generally considered a core aspect of ASD, because they account for the socio-emotional aspects of behavior, even though they cannot explain the whole set of symptoms. So far, experimental research on social cognition treatments (not addressing gifted populations) focused on the cognitive component of empathy [14]-[17]. Hadwin and colleagues [14] developed a program, based on learning patterns aimed at avoiding mistakes to teach emotional and mental state comprehension and various types of playing abilities. Golan and Baron-Cohen [15] developed a 10 weeks computerized training for adults with autism, consisting in a DVD that elicits mind reading. To promote the same ability in children with high functioning ASD (4 - 7 years of age), another DVD, “The Transporters”, was developed by Golan and collaborators [16]. Through a series of 15-minute cartoons, an autism-friendly context for learning was created. The main characters are motor vehicles with human facial expressions representing both basic and complex emotions. Children, attracted by the vehicles, observe these expressions and become familiar with the underlying emotions. In sum, some social cognition treatments used explicit teaching methods, such as "drill and repeat practice", while some others were based on implicit teaching. Nevertheless, several questions about the possibility of generalizing the abili- 
ties learnt by the children and their effect on social functioning still remain unanswered. Additionally, if the aim is to facilitate the transfer of these abilities to everyday life, these treatments need to be combined with ecological approaches.

Conversely, there are techniques whose effectiveness has not already been proven, even though they seem promising in clinical contexts [18], such as the social reading technique introduced by Carol Gray [19]. Gray suggests three types of activities which can be used individually and in combination. The first technique includes social stories [20], that can be written by parents or professionals to describe social situations which prove difficult or confusing for children with ASD. The aim is to facilitate comprehension and suggest appropriate behaviors. Several studies have tested the effectiveness of social stories, which proved effective both in decreasing disruptive behaviors in children with ASD [21], and in improving their social skills in play [22]. A second activity includes "social reading" [19], where the adult and the child with ASD analyze together social scenes represented in the videos. After watching a given scene in a video, the child is asked to "read" it, i.e. to identify places, objects, people, events, gestures, and conversations he/she sees and hears. At this stage, the adult supports the child without explicitly directing his/her attention on relevant events. The objective is that the child and the adult first read the scene one independently from the other, and then share their "readings". The general aim is to enhance the child's comprehension of social situations by helping him/her to focus his/her attention on verbal and non verbal cues he might have neglected, such as facial expressions, prosodic stresses, context, etc.

The third area of activities includes a series of social supports which may facilitate the learning of new social skills. For instance, there are aids aiming at increasing childrens' autonomy, such as the "instruction blackboard", the "social reading folders", the "reading bookmark", the "social calendars". What is particularly interesting in Gray's proposal, especially in social reading, is that this technique improves not only the way the child with ASD understands social situations, but also the way the adult understands the child's comprehension of the social world.

This study describes the intervention with a gifted child with ASD in the social cognition area based on "social reading” technique, described above [19]. The objectives were to improve the child's capability of decoding social behavior, and to enhance his mentalistic reasoning.

\section{The Case Study: Child SC}

SC is the pseudo-acronym of a 9.2-year-old boy who was brought by his parents to a neuro-psychiatric Center for his social difficulties and isolation when he was attending the fourth year of primary school. He was very bright for his age and his school marks were excellent. His tendency towards self-isolation and his general social problems were evident especially at school. He was extremely precise, inflexible with home routines and insisted on some small rituals. Although his problems had appeared when he was very young, he had never received a neuro-psychiatric assessment, so no previous diagnosis had been made before arriving to the Center. During the interview with the parents, they said that SC had had those problems "nearly all his life", but they had underestimated them for a long time due to the child's brilliant cognitive performance. Teachers praised the brilliant results he achieved in all subject matters (except in drawing), but they reported severe difficulties in interaction with peers. SC was depicted as clumsy in social interaction ("he doesn't know what to say and what to do", "he makes repetitive jokes", "he doesn't understand the limits"), rigid, little inclined to find an agreement ("he respects only his own rules") and inclined to reject every objection ("my head says I must do this way"). The parents added that he did not seem to be able to put himself in somebody else's shoes ("he lacks empathy") and had reactions which were inappropriate for his age (for example, if he stumbled and fell without really hurting himself, he would immediately start crying). SC's parents also reported that they had to continually insist to have him look at people in the eyes when talking to them. Conversely, he seemed to be able to understand prosody changes in parents' speech. While he was nearly pedantic in his own discourse, he looked astonished when confronted with idiomatic expressions and figurative language usages in others' discourse.

Very early he showed a special interest for numbers: as young as 3 years old, he spent entire afternoons rewriting the bingo matrices, copying pages and pages of numbers or staring at the mumbers of digital watches. When he was about 4 - 5 years old, he knew the multiplication tables, how to do additions and subtractions with two digits (also with relative numbers) and when distracted from his interest, which absorbed him completely, he would answer: "No! Don't you see I'm busy with numbers!”. At nursery school, he showed nearly no interest in playing with the other children. When he started primary school, he became almost unmanageable: he would 
stand up continually to go and write on the backside of the blackboard or stand apart from his classmates to draw the solar system on the desk.

\subsection{The Cognitive Assessment}

At WISC III [4] [23], 'SC’s full scale IQ was 136, verbal IQ was 146 and performance IQ was 117. The Factorial Quotients showed the following values: Verbal Comprehension $=141$; Freedom from Distractibility = 155; Perceptual Organization = 110; Processing Speed $=155$. Table 1 shows the scaled scores of each subtest.

TIQ was within the gifted range, namely in the moderately gifted area, according to the classification developed by Gross [24]. There was a 29 points discrepancy between VIQ and PIQ. Performance seemed more uniform in the verbal area, where SC excelled as for lexical definition, information recall, categorizing ability and problem-solving, and the scores even reached the ceiling effect in the Arithmetic and Digit Span substests. Performance Scale results were more heterogeneous, showing a relative deficit in the Picture Arrangement subtest. Qualitative analysis showed that SC was excessively attracted by the details of the pictures and connected images without rechecking the overall coherence between them.

During the assessment, SC tried to monopolize the conversation keeping it focused on numbers and planets, which are his specific interests, and showed poor abilities in monitoring his interlocutor's nonverbal signals. He used eye contact in an irregular way, and his facial and vocal expressions were also quite poor. Upon request to perform his family's drawing, SC provided the picture reproduced in Figure 1, below. As can be noticed, the figurative aspects of the human characters are reduced to extremely schematic silhouettes, and the main focus is on quantification and verbal categorization of the family members. SC drew the partitions of meters on the vertical axis, against which he put the silhouette of his own image and that of all the members of his family to show how tall each one is. Moreover, on the top of the figure of each member he wrote the name, the role, the age and the height. (For privacy reasons, names and roles have been cancelled).

In the semi-structured interviews of Autism Diagnostic Observation Schedule (ADOS) [25] [26], SC systematically used quantitative and numerical criteria in handling psychological topics such as friendship, social concerns and emotions. He talked about friendship in terms of percentages, using graphic diagrams with double arrows. For instance, he asked how many arrows there should be if he had 1500 friends, then started counting by himself and came to the following result: 2.251 .500 .

On the basis of his clinical history, as well as from observational data and questionnaires (his standard score at KADI [27] was 114, indicating a high probability of Asperger Syndrome), and the results of the cognitive and social cognition (see below) assessment, SC received a diagnosis of Asperger Syndrome, according to the DSM IV-TR criteria [3] (N.B. The diagnosis was made before the release of DSM-5).

\subsection{Social Cognition Assessment}

To assess social cognition, the following instruments were used:

- “Social Perception", Theory of Mind, and Affect Recognition, from NEPSY II [9] [28].

- The Eyes Test version from the computerized battery Autismo e competenze cognitivo-emotive” (“Autism

Table 1. Scaled scores of WISC-III.

\begin{tabular}{cccc}
\hline \multicolumn{2}{c}{ VERBAL SCALE } & \multicolumn{2}{c}{ PERFORMANCE SCALE } \\
\hline Subtest & Scaled score & Subtest & Scaled score \\
\hline Information & 18 & Picture completion & 13 \\
Similarities & 17 & Coding & 11 \\
Arithmetic & 19 & Picture arrangement & Block design \\
Vocabulary & 15 & Object assembly & 12 \\
Comprehension & 15 & Symbol searh & 14 \\
Digit span & 19 & Mazes & 16 \\
\hline
\end{tabular}

${ }^{1}$ When this study was carried out, WISC-III was the most recent version available in Italian. 


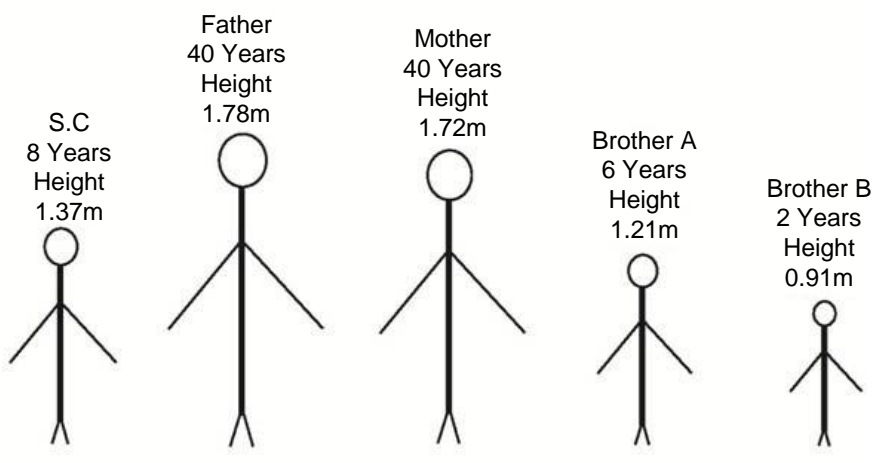

Reproduced from the original child's drawing

Figure 1. SC's family drawing. Legend: Years and height of the family members (on the top of each figure).

and cognitive-emotional skills") [29].

- The battery “Abilità Pragmatiche del Linguaggio-APL Medea” ("Language pragmatic abilities-APL Medea”) [30].

The outcomes of these tests were used as pre-test measures before the treatment.

Theory of Mind includes tasks exploring various types of mentalistic reasoning (e.g. the attribution of mental states, the comprehension of bluff and double bluff, of non-literal language and the comprehension of the appropriate matching between social situations and the facial expression of emotions of the character involved in these situations). Affect recognition evaluates the ability of recognizing emotions from photos of children's faces (neutral feelings, happiness, sadness, fear, anger and disgust). The Eyes Test [29] is a task where subjects must read the mind through the gaze. The child is asked to choose the mental state that matches the photo among four options. Finally, the APL [30] test evaluates various pragmatic aspects of language. Verbal and iconic metaphors evaluates the ability to understand sentences metaphorically. Comprehension of the implicit meaning evaluates the capability of making inferences about a situation on the basis of linguistic cues; Comics evaluates the capability of understanding conversational structures; Situations evaluates the understanding of certain linguistic expressions in social interaction, and Colour game evaluates the capability to consider the other's mental representations in communication.

Performances in the social cognition measures were both irregular and lower than expected. The scaled score was borderline in Theory of Mind (7), and below the limit in Affect Recognition (3). In the Eyes Test, z-score was -3.5. The general score in the APL was within the normal range, but, in light of the very high VIQ (146), we might consider that there were some difficulties in Verbal and iconic metaphors $(\mathrm{z}=-0.93)$. In sum, SC showed markedly impaired performances in social-perceptual tasks (Affect recognition and Eyes test) and less severe problems in social-cognitive tasks. In these cases, SC got confused with stories requiring complex inferential reasoning abilities, as measured by the bluff and double bluff items (Theory of mind-part A) and the APL's Verbal and iconic metaphors subtest (see Figure 2 and Figure 3).

\section{Treatment and Assessment of Progress}

Child SC was pre-tested on February with the whole battery described above. The treatment consisted of 14 


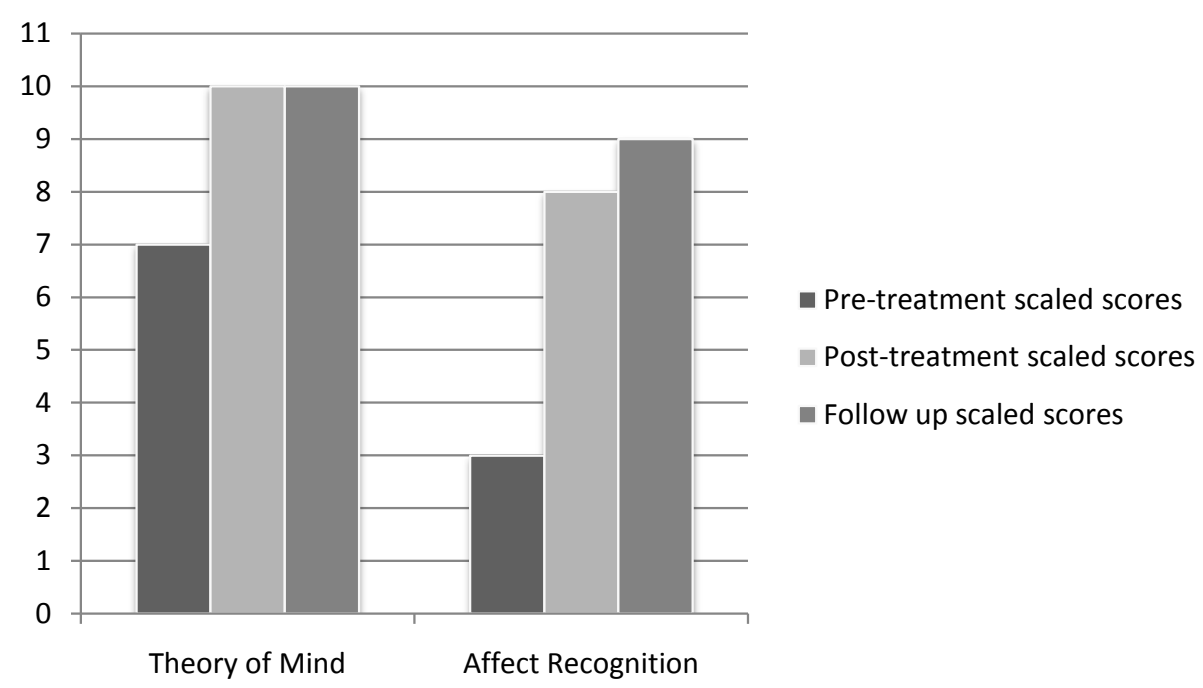

Figure 2. Theory of mind and affect recognition pre-treatment, post-treatment and follow up scores.

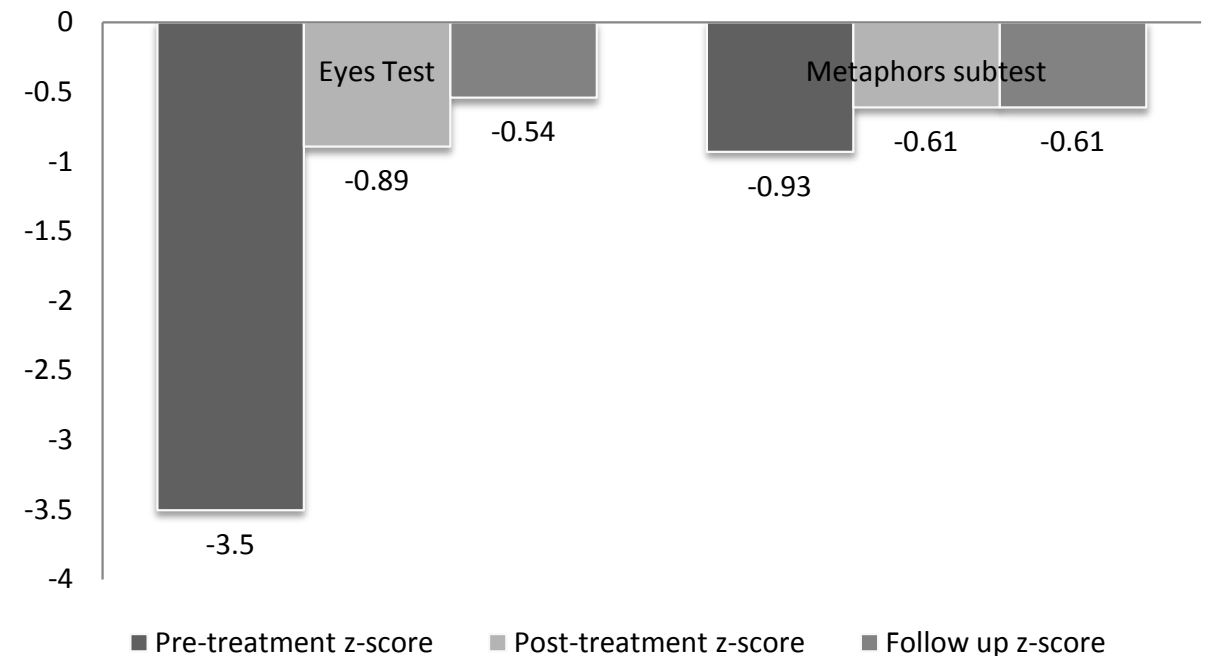

Figure 3. Eyes test and APL metaphors subtest pre-treatment, post-treatment and follow up scores.

sessions of 90 minutes each, based on interactions between a psychologist and the child, starting from March until June. The sequence of the session was always the same: (1) opening, (2) first activity: social reading with film clips, (3) break, (4) second activity, (5) closure.

The first activity implemented during session (b) used videos showing social stories. Twelve short sequences of about 3 minutes were chosen from an Italian television series. The sequences showed everyday life situations and the main characters were children of the same age as SC. The implementation of the videos were based on an adaptation of Gray's "Social reading" technique [19]. SC and the adult watched a video together, then the adult would invite the child to verbalize his "reading" of the situations shown in these videos. Afterwards, the adult would express his own point of view about the elements that could be shared with the child, and subsequently suggest new keys of interpretation. The reading was guided by observation grids provided by the adult and focused on various elements, such as physical context, objects, people, gestures and conversation. By using the videos with and without sound, stop-motion and analysis of the most complex sequences, attention was oriented towards hints and signals such as facial and prosodic expression. The child was also induced to reflect on the five Ws of social situations: Who, What, When, Where, Why. On these grounds, the child and the adult could face the social scene presented in the video as a form of social task to be solved (see Table 2). 
Table 2. Objectives and observation grid related to an activity represented in video n.3.

\begin{tabular}{|c|c|c|}
\hline Example from the Video n.3 & Objectives & Observation grid \\
\hline \multirow{14}{*}{$\begin{array}{l}\text { The video presents an interaction } \\
\text { between two characters, a teacher and a } \\
\text { pupil. During the break, the pupil stands } \\
\text { alone, far from his schoolmates, with a } \\
\text { sad expression because he realizes he is } \\
\text { not good at drawing. The teacher gets } \\
\text { near him and tries to comfort him by } \\
\text { reporting on a personal experience when } \\
\text { he himself was a child. He made an ugly } \\
\text { drawing, and his teacher asked him } \\
\text { whether he had spilled a cup of coffee } \\
\text { and milk on his sheet of paper. }\end{array}$} & & "Who are the characters?" \\
\hline & 1. Promoting the comprehension of the & "What are the relevant parts of X's face we \\
\hline & targeted emotion: & must look at to understand how he feels?” \\
\hline & a) Expression & “What does X say?” \\
\hline & b) Hypotheses about internal and external & "How does X say it?" \\
\hline & causes. & "What happened?” \\
\hline & & "What do you think X thought?" \\
\hline & $\begin{array}{l}\text { 2. Detecting the indicators of the intensity of } \\
\text { the targeted emotions as manifested by the } \\
\text { characters. }\end{array}$ & $\begin{array}{l}\text { Learning how to use the emotion } \\
\text { thermometer. }\end{array}$ \\
\hline & & "Which other words can we use to express \\
\hline & $\begin{array}{l}\text { 3. Stimulating the linguistic expression of } \\
\text { the targeted emotion. }\end{array}$ & $\begin{array}{l}\text { this emotion?" } \\
\text { (Question to address for each relevant } \\
\text { emotion) }\end{array}$ \\
\hline & & "What could X do to feel better?" \\
\hline & $\begin{array}{l}\text { 4. Promoting the regulation of the targeted } \\
\text { emotion. }\end{array}$ & $\begin{array}{l}\text { "When you feel sad what can you do to } \\
\text { conceal it?" }\end{array}$ \\
\hline & & "What can you do to feel better?" \\
\hline & $\begin{array}{l}\text { 5. Perceiving an implicit level of } \\
\text { communication in the conversation between } \\
\text { the two characters. }\end{array}$ & $\begin{array}{l}\text { "Why does the teacher ask whether X spilled } \\
\text { coffee and milk on his drawing?" }\end{array}$ \\
\hline
\end{tabular}

During the activities, a bottom-up and a top-down approach were integrated. The former starts from the "data" to empower the observation of signals (e.g. postures, gazes, voice tone, etc.) which can activate social cognition processes. The latter offers knowledge and information on social scripts, rules and cultural conventions, in order to facilitate mentalistic inferences. After a break, a second phase was implemented on isolated stimuli (facial and vocal expressions), in short multi-step activities. As regards prosody, for instance, SC had to recognize the emotions and intentions underlying verbal expressions. In some cases, these were semantically neutral while in others they expressed surprise, embarrassement, doubt, etc., and SC had to recognize the possible mismatch between verbal content and other cues, prosodic and facial. At the same time, detecting these mismatches stimulated the enrichment of mentalistic vocabulary. Other joint activities were playing with cards, meant as a form of social problem-solving to foster the awareness of various distinctions. On the one hand, the distinction between different activities, each embodied in different types of cards: “Thinking cards", "Doing cards" and "Feeling cards". On the other hand, the distinction between the characters and the subject in the first person (what the character thinks or does or feels versus what $I$ would think or $I$ would do or $I$ would feel) [31]. Finally, joint book reading was also practiced. To stimulate the understanding of mental states (intentions, wishes, emotions), stories eliciting complex inferential processes were chosen.

At the end of the treatment (June), the same battery was used for the post-test, and after five months (November), a follow-up assessment took place. The post-treatment assessment addressed only the areas which were impaired at pre-treatment stage (Affect recognition, Theory of mind, subtest Metaphors-APL). All the scores increased (Affect Recognition: from 3 to 8; Theory of mind: from 7 to 10; Eyes Test: from -3.5 to -0.89 ), except Metaphors-APL (z: -0.93 vs -0.61) which did not change significantly (Figure 2 and Figure 3).

In addition to these measures, to verify the impact of the intervention on social functioning at post-test, interviews were conducted with the parents who also reported the teachers' point of view about their child. On the whole, the data suggested that SC looked more flexible and more able to take part to everyday interactions, although he tended to address adults (especially his parents) more frequently than his peers. According to this parents, SC looked more curious about the rules that govern the social world, especially those that people normally consider as implicit. At the follow up, the results were essentially stable: the score was 9 in Affect Recognition; 10 in Theory of mind; -0.54 in the Eyes Test; -0.61 in Metaphors (Figure 2 and Figure 3).

At that stage, the child was also asked to "read" the $13^{\text {th }}$ video of the Italian series, which is the last one and represents a form of final check of whole activity of social reading. The qualitative data gathered through the observation grid (see Table 2) showed that SC used the set of rules acquired during the treatment to "read" social contexts. During the follow up, we interviewed the parents again, who confirmed SC's improvements in social interaction and understanding of social world, and the teachers agreed with the parents' opinion. 


\section{Discussion}

This article described an intervention implemented with a gifted child with ASD to sensitize him with respect to some social cognition abilities which had been diagnosed as markedly deficitary, such as mentalistic reasoning and affect recognition from emotional expression. To this end, we planned a set of activities mainly based on videos using Gray's technique of “social reading” [19] where two participants must watch some social scenes together and share their interpretations about the contents of these scenes. To assess the impact of the treatment, a battery of social cognition was used at three different times: pre-test, post-test and follow-up. At the end of the treatment and in the follow up, the social cognition measures highlighted some improvements, for instance in the recognition of mental states from facial expression and gaze and in the mentalistic reasoning processes.

These improvements might reflect either the familiarization with the activities practiced during the treatment, or, at a deeper level, a more strategic approach to the tests, or both. For instance, in Affect Recognition, SC explicitly verbalized his ongoing exploration of the stimuli ("I'm paying attention to the eyes", "I'm looking at the mouth...", "I can see it also from the eyes"). In the "Eyes Test”, SC requested to see the stimulus a second time (which is allowed by the task) before selecting the suitable verbal label. Therefore, better controlled perceptual processes yielded better focused answers. Overall, the results were in line with the literature on gifted children, which claims that these children have good chances to extend their learning abilities to novel domains [2].

To better illustrate how these improvements took place, we will describe some sequences of the treatment. First of all, since the first session, SC brought one of his favourite books, "The Number Devil: A Mathematical Adventure" [32] and proposed the psychologist to work together on the activities described in this book. The psychologist welcomed the child's proposal in the form of a social negotiation which had to include also some tasks in the social cognition domain. From that moment onwards, SC manifested a strong motivation to come to the treatment sessions, as witnessed by his parents, although he always tried to monopolize the psychologist's attention towards his favourite topic, i.e. numbers. By accepting SC's characteristics as strenghts and not simply as weaknesses, for instance his orientation towards details and his ability to memorize scripts, the psychologist implemented systematic joint activities to stimulate the child's understanding of social behavior. SC's inflexibility, which had always been reported by his family and his teachers as a typical weakness, proved helpful during the treatment because it supported a systematic exploration of social scenarios through videos.

As an example of this process, we will describe a certain moment of a session (see Table 2). The video presented an interaction between two characters, a teacher and a pupil. During the break, the child was sitting alone, far from his schoolmates, with a sad expression on his face. The teacher got near him with some comforting words: "Hey! What a little muzzle (in Italian, this expression means "what a sad face”) you've got there”. SC looked impressed and disoriented by this phrase. His immediate reaction was to retrieve a typical dictionary definition of the term "muzzle". "Muzzle?! He is not a dog... the muzzle is the projecting part of the face including the nose and mouth of an animal like a dog or a horse", objecting to the acceptability of this use of the word "muzzle”. Actually, in Italian, the figurative meaning of "muzzle” would be, in this context: “pouting, making a sad expression pushing the bottom lip forward”. The psychologist stimulated SC to orient his attention towards the character's upper lip and this, eventually, convinced SC to accept the figurative meaning of "muzzle”. Further to the analysis of this detail, SC's attention was systematically oriented towards cues having to do with eyes, posture and prosody, to draw inferences about the character's internal states.

Another way for the psychologist to exploit SC's strenghts was to rely on the child's spontaneous tendency towards quantification. To this end, the psychologist invited him to use the "emotion thermometer" [33] to indicate the intensity of the character's emotions on a 0 to 10 scale. SC first attributed numerical values to the characters' emotions, and afterwards he had to transcode these numbers into the corresponding linguistic nuances (sad, disappointed, sorry, saddened, discouraged, distressed, desperate). Then, the psychologist presented SC a range of linguistic labels and showed him the correspondence between these words and some prototypic facial expressions. Eventually, SC identified the teacher-and-pupil sequence in the video, and elaborated a sort of script of this sequence he spontaneously translated into the following flow chart.

"What did the teacher do?

1. He looked at X's face.

$\Downarrow$

2. He asked X: “Are you alright?”

$\Downarrow$ 
3. The teacher narrated an episode of his life, when something similar happened to him, saying "I understand how you feel because it also happened to me".

$\Downarrow$

4. The teacher asked $\mathrm{X}$ if he could help him.

$\Downarrow$

5. The teacher helped X.”

This way of learning clearly evokes experiences reported by some individuals with high functioning ASD. For instance, harking back to Asperger, Temple Grandin [34] emphasized the lack of implicit knowledge of social rules in children with ASD. "Hans Asperger stated that normal children acquire social skills without being consciously aware because they learn by instinct. In people with autism 'Social adaptation has to proceed via the intellect.' [...] Autistic children have to learn social skills systematically, the same way they learn their school lessons." (p. 155).

SC used similar strategies. Once he inferred a social script further to the interpretation of a given scene, he would often reuse this script and adapt it to its personal case. He spontaneously verbalized the "discoveries" he made during the readings of these scenes. For instance, he once said: "Did you know that when two people are talking to each other and one of them averts one's gaze, this means he is not interested in the topic?"

The results of this case study confirms the validity of the social reading technique for children with highfunctioning ASD, as suggested by Gray [19]. To this end, we might think that gifted children offer richer potentialities than other categories, thanks to their tenacity and will to learn, that enable the adult to expand their social repertoire.

\section{Conclusion}

SC's high intellectual potential and strong motivation supported his learning processes. Nevertheless, it is harder to foresee to what extent the child will be able to generalize these acquisitions to everyday life contexts appropriately. Moreover, the apparent success of the treatment does not guarantee that SC will autonomously and flexibly interpret the correct meaning of communicative exchanges. Research on social cognition shows that a constant and flexible ability to "tune in" to the emotional world of other people is an essential tool to cope with everyday life interactions [10].

\section{References}

[1] American Psychiatric Association (2013) Diagnostic and Statistical Manual of Mental Disorders. 5th Edition, American Psychiatric Publishing, Arlington.

[2] Lovecky, D.V. (2004) Different Minds. Gifted Children with AD/HD, Asperger Syndrome, and Other Learning Deficits. Jessica Kingsley, London.

[3] American Psychiatric Association (2000) Diagnostic and Statistical Manual of Mental Disorders. $4^{\text {th }}$ Edition, Text Revision, Author, Washington DC.

[4] Wechsler, D. (1993) Wechsler Intelligence Scale for Children-WISC-III. The Psychological Corporation, San Antonio.

[5] Foley-Nicpon, M., Assouline, S.G. and Stinson, R.D. (2012) Cognitive and Academic Distinctions between Gifted Students with Autism and Asperger Syndrome. Gifted Child Quarterly, 56, 77-89. http://dx.doi.org/10.1177/0016986211433199

[6] Wechsler, D. (2003) Wechsler Intelligence Scale for Children-WISC-IV. The Psychological Corporation, New York.

[7] Neihart, M. (2000) Gifted Children with Asperger’s Syndrome. Gifted Child Quarterly, 44, 222-230. http://dx.doi.org/10.1177/001698620004400403

[8] Assouline, S.G., Foley Nicpon, M. and Doobay, A. (2009) Profoundly Gifted Girls and Autism Spectrum Disorder: A Psychometric Case Study Comparison. Gifted Child Quarterly, 53, 89-105. http://dx.doi.org/10.1177/0016986208330565

[9] Korkman, M., Kirk, U. and Kemp, S. (2007) NEPSY. 2nd Edition, The Psychological Corporation, San Antonio.

[10] Frith, C. (2008) Social Cognition. Philosophical Transactions of the Royal Society B: Biological Sciences, 363, 20332039. http://dx.doi.org/10.1098/rstb.2008.0005

[11] Frith, C.D. and Frith, U. (2008) Implicit and Explicit Processes in Social Cognition. Neuron, 60, 503-510. http://dx.doi.org/10.1016/j.neuron.2008.10.032 
[12] Baron-Cohen, S. (2009) Autism: The Empathizing-Systemizing (E-S) Theory. Annals of the New York Academy of Sciences, 1156, 68-80. http://dx.doi.org/10.1111/j.1749-6632.2009.04467.x

[13] Baron-Cohen, S., Leslie, A. and Frith, U. (1985) Does the Autistic Child Have a "Theory of Mind”? Cognition, 21, 3746. http://dx.doi.org/10.1016/0010-0277(85)90022-8

[14] Hadwin, J., Baron-Cohen, S., Howlin, P. and Hill, K. (1996) Can We Teach Children with Autism to Understand Emotions, Belief, or Pretence? Development and Psychopathology, 8, 345-365. http://dx.doi.org/10.1017/S0954579400007136

[15] Golan, O. and Baron-Cohen, S. (2006) Systemizing Empathy: Teaching Adults with Asperger Syndrome or High Functioning Autism to Recognize Complex Emotions Using Interactive Multimedia. Development and Psychopathology, 18, 591-617. http://dx.doi.org/10.1017/S0954579406060305

[16] Golan, O., Ashwin, E., Granader, Y., Mcclintock, S., Day, K., Leggett, V. and Baron-Cohen, S. (2010) Enhancing Emotion Recognition in Children with Autism Spectrum Conditions: An Intervention Using Animated Vehicles with Real Emotional Faces. Journal of Autism and Developmental Disorders, 40, 269-279. http://dx.doi.org/10.1007/s10803-009-0862-9

[17] Baron-Cohen, S., Golan, O. and Ashwin, E. (2012) Educational Cognitive Neuroscience: Designing Autism-Friendly Methods to Teach Emotion Recognition. In: Della Sala, S. and Anderson, A., Eds., Neuroscience in Education: The Good, the Bad and the Ugly, Oxford University Press, Oxford, 299-311. http://dx.doi.org/10.1093/acprof:oso/9780199600496.003.0092

[18] Reynhout, G. and Carter, M. (2006) Social Stories ${ }^{\mathrm{TM}}$ for Children with Disabilities. Journal of Autism and Developmental Disorders, 36, 445-469. http://dx.doi.org/10.1007/s10803-006-0086-1

[19] Gray, C. (1995) Teaching Children with Autism to "Read” Social Situations. In: Quill, K.A., Ed., Teaching Children with Autism: Strategies to Enhance Communication, Albany, Delmar, 219-242.

[20] Gray, C. (1993) The Original Social Stories Book. Future Horizons, Arlington.

[21] Rhodes, C. (2014) Do Social Stories Help to Decrease Disruptive Behaviour in Children with Autistic Spectrum Disorders? A Review of the Published Literature. Journal of Intellectual Disabilities, 18, 35-50. http://dx.doi.org/10.1177/1744629514521066

[22] Quirmbach, L., Lincoln, A., Feinberg-Gizzo, M., Ingersoll, B. and Andrews, S. (2008) Social Stories: Mechanisms of Effectiveness in Increasing Game Play Skills in Children Diagnosed with Autism Spectrum Disorder Using a Pretest Posttest Repeated Measures Randomized Control Group Design. Journal of Autism and Developmental Disorders, 39, 299-321. http://dx.doi.org/10.1007/s10803-008-0628-9

[23] Orsini, A. and Picone, L. (2006) WISC-III: Contributo Alla Taratura Italiana. Italian Version of Wechsler (1991). Organizzazioni Speciali, Firenze.

[24] Gross, M.U.M. (2004) Exceptionally Gifted Children. Routledge, New York.

[25] Lord, C., Rutter, M., Dilavore, P.C. and Risi, S. (2000) Autism Diagnostic Observation Schedule. Western Psychological Services, Los Angeles.

[26] Tancredi, R., Saccani, M., Persico, A.M., Parrini, B., Igliozzi, R. and Faggioli, R. (2005) Autism Diagnostic Observation Schedule. Giunti OS, Firenze.

[27] Krug, D.A. and Arick, J. (2003) Krug Asperger’s Disorder Index. Pro-Ed., Austin.

[28] Urgesi, C., Campanella, F. and Fabbro, F. (2011) NEPSY II: Contributo Alla Taratura Italiana. Italianversion. Giunti OS, Firenze.

[29] Pinelli, M. and Santelli, E. (2005) Autismo e Competenze Cognitivo-Emotive. Autism and Cognitive-Emotional Skills, Erickson, Trento.

[30] Lorusso, M.T. (2009) APL-Medea: Abilità pragmatiche del linguaggio. APL-Medea: Language Pragmatic Abilities, Giunti OS, Firenze.

[31] Di Pietro, M. and Dacomo, M. (2007) Giochi e attività sulle emozioni. Games and Activities about Emotions, Erickson, Trento.

[32] Enzensberger, H. (1998) The Number Devil. Henry Holt, New York.

[33] Attwood, T., Callesen, K. and Møller Nielsen, A. (2008) The CAT-Kit: Cognitive Affective Training Kit. Future Horizons, Arlington.

[34] Grandin, T. (2006) Thinking in Picture: My Life with Autism. Vintage Books, New York. 